\title{
Tools and Techniques Adapted for Teaching Software Engineering Topics Remotely during the COVID-19 Pandemic
}

\author{
Md. Farhad Alam Bhuiyan \\ Green University of Bangladesh \\ Dhaka, Bangladesh \\ farhad@cse.green.edu.bd
}

\author{
Musfiqur Rahman \\ General Assembly \\ Toronto, ON, Canada \\ musfiqur.rahman@ga.co
}

\author{
Fairuza Laila \\ University of Dhaka \\ Dhaka, Bangladesh \\ fairuza-2017314976@cs.du.ac.bd
}

\author{
Sarkar Tanveer Ahmed \\ University of Dhaka \\ Dhaka, Bangladesh \\ rumee@cse.du.ac.bd
}

\author{
Ishtiaque Hussain \\ Pennsylvania State University - Abington \\ Abington, PA, USA \\ ihussain@psu.edu
}

\begin{abstract}
To stop the spread of the COVID-19 virus, educational institutions abruptly switched from in-person to online, remote mode of teaching without giving educators the necessary tools and training. In this paper, we focus on the Software Engineering Education \& Training (SEET) courses at the university levels and address questions like: What tools and techniques did they adapt to handle the modality transition challenges? What lessons they learned and what would they do differently the next time? What are the students' perspective on these, etc.? We interviewed 16 SEET educators from different countries around the world; followed by surveys of more than 300 educator and student participants. Our empirical study found some common themes of challenges, as well as suggestions on tools and techniques to overcome them.
\end{abstract}

\section{Introduction}

When classes switched from in-person to remote/online modality due to the COVID-19 pandemic, instructors did not have much choice but to adapt new tools, techniques, teaching environments and styles, etc., in an ad-hoc basis without proper training. Although teaching courses online/remotely have their own generic and common struggles, since Software Engineering Education and Training (SEET) topics are generally project-based, team-oriented and require lots of interactions among the different stakeholders, they have posed some unique challenges.

Many universities provide licensed software products for course management systems, however, they rarely provide directives on tools for class engagement, team-based project development, management and interactions. As a result, SEET instructors and the students were scrambling for new ideas of class engagement, content delivery, team collaboration, course evaluations and other things, and were experimenting with different tools, techniques and methodologies.

Was there any common set of tools that they used and found particularly useful that could be used moving forward even after things go back to 'normal'? What were some of the challenges in deciding on these tools and adapting them? Instructors and students in universities in developed countries are required to use the licensed online learning and course management tools, but how did others, especially in developing countries where they do not have such infrastructure, cope up with this sudden switch in teaching modality?

In this empirical study we tried to learn from different software engineering educators across the world about this ad-hoc introduction of distance learning in software engineering, and share the ideas, tools, techniques and approaches that they used to overcome some of the issues. We also solicited students perspective on these. Specifically, in this paper, after giving some context on the challenges, some of which are very common to other online courses - we try to find answers to the following Experience/Empirical Questions (EQs):

- EQ1: What tools and techniques did SEET educators adapt to handle some of the modality transition challenges?

- EQ2: What lessons did SEET educators learn and what are the improvement suggestions?

For both the questions, we also solicit feedback from students and try to compare the perspectives. The main contribution of this paper is to share the 
findings on the above experience, empirical questions on this "pandemic teaching" of software engineering in undergraduate and graduate level university courses. The paper also contributes by making all the survey questions and the responses public in its companion website [1] for further study and collaboration.

The remainder of this paper is structured as follows: Section 2 discusses related work, Section 3 discusses the approach and experiment setup for this study; Section 4 discusses the findings on the empirical and experience questions, Section 5 mentions the limitations and threats to validity of our study; and finally sections 6 and 7 provides discussion, future research direction and conclusion to the paper.

\section{Related Work}

Online courses are not new. Many universities offer online courses and enjoy higher enrollment of students from non-traditional backgrounds and reported advantages like greater accessibility, flexibility, reduced commute time and lower carbon footprint [2, 3]. Some universities have been delivering Software Engineering Education and Training (SEET) courses online successfully for over 30 years with various innovative and flexible approaches [4]. There is research that focused on these online SEET courses: e.g., Gannod et al. [5] showed how inverted classrooms are used to teach SEET courses. Jacobsen et al. [6] performed comparative studies among various communication platforms used for distant teaching of graduate SEET courses. Yoshida et al. [7] developed online systems to facilitate distance learning for programming and SEET courses. Cloete et al. [8] investigated network-centric distance learning and software engineering.

With distance learning being different to conventional in-class education system, many educators were skeptical about how successfully the learning goals of SEET can be achieved through an online platform. Edwards [9] specifically asked if asynchronous, online courses can deliver quality SEET courses and performed a case-study to identify some limitations of distance learning and proposed effective alternatives. Ellis [10] conducted surveys and reported students' opinion on comparison between online and in-class SEET courses. More recent SEET research in this area mainly focused on proposing various methods of teaching different aspects of SEET [11, 12].

However, although almost $70 \%$ of U.S. universities reported online classes as their future strategy, online-only learning has many disadvantages, e.g., weak student engagement, isolation, technology interruption, etc. $[13,14,15]$. These became particularly challenging due to the COVID-19 pandemic since all family members were now staying home, sharing the Internet and sometimes even the very electronic devices that are used for the online classes. These are adding to the stress, isolation, learning difficulties, decreased productivity and more interruptions from family members or pets [16]. Education researchers are working on finding ways to cope up with the challenges and changes while maintaining students' learning outcome $[17,18,19]$. SEET specific researchers have shared their experience mainly on the challenges and the structural changes they adapted for the transition $[20,21,22,23,24]$. However, in this paper, after briefly discussing the different challenges both the educators and students reported for distance learning of SEET courses during the pandemic, we present the numerous tools and techniques they adapted in their courses. In this regard, our work is related to Moster et al. [25], where they proposed a study on the use of communication tools for remote and hybrid team collaboration for software development.

\section{Empirical Study Setup}

This empirical study was a multi-step study. As a first step, around mid-June of 2020, we contacted participants of the 2019 and 2020 International Conference on Software Engineering, Software Engineering Education and Training (ICSE-SEET) conferences and requested them for a 30 minute, semi-structured "Zoom" interview if they met the following criteria: (i) taught an university-level SEET course during the pandemic, (ii) previously taught the same course "in-person" and (iii) had to switch to "remote, online" mode due to the pandemic. The rationale behind these selection criteria was to seek the experience, challenges educators are facing for the modality transition and the tools and techniques they are adapting to tackle them. We also approached SEET educators in our professional network as well as performed manual, search-engine lookup for SEET educators, world-wide.

As Figure 1 shows, we were able to conduct 16 semi-structured interviews of SEET educators (13 males, 3 females) from 11 different countries spanning 5 continents. On average, each interview was about 35 minutes long, all the interviews were video-recorded with consent and the interviewees/participants ranged from lecturers to full professors in their designations. With Zoom's auto-transcription feature, we transcribed all the interviews and later anonymized and thoroughly analyzed them for common themes.

Next, we used these common themes to come up 


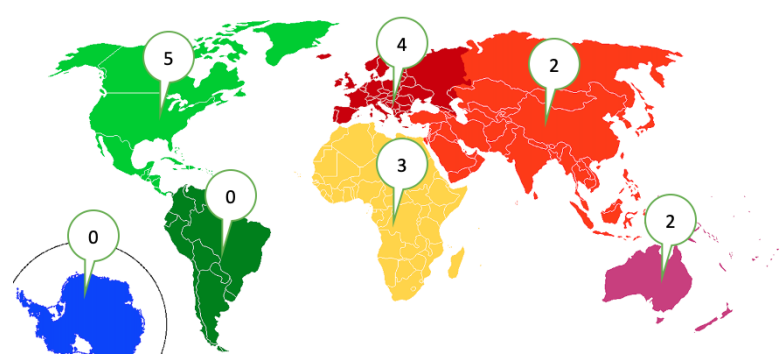

Figure 1. Interview participants' distribution across different continents. We took total 16 interviews (13 male, 3 females). Original world continents map is "licensed for reuse with modification", taken from Google Images.

with survey questions for both the SEET educators and students. The purpose of these surveys were to reach a broader SEET community and solicit quantifiable data and if possible, gather further feedback on them. Each version of the survey had questions in three sections: firstly, basic demography and background related questions (e.g., course level, class size, and from which country they offered/took the course), secondly, questions regarding their experience, challenges and tools that they used to overcome teaching/taking the course online and thirdly, soliciting improvement suggestions. Moreover, for each survey question, we had the option for participants to write down, elaborate and share their opinion or insights.

We then obtained our Institutional Review Board's (IRB) certificate on the research involving human subjects and approval for the survey questions and ensured that we do not collect any personally identifiable data of the participants. Finally, we published the survey and solicited voluntary participation utilizing social media platforms, mainly, Facebook, Twitter and LinkedIn. We also approached our colleagues and friends and requested them to circulate the survey links among their professional network and their students. Furthermore, using a popular search engine, we randomly picked two universities from almost all the countries in the world, looked up their computer science department or program contact person and sent out more than 380 emails soliciting survey participation from both the educators and the students. Our surveys were open for participation for three weeks, starting in late-September of 2020.

\section{Results}

In this section, we present some metadata on our survey participants, briefly discuss the common, repeated theme of "remote, online" class transition challenges that came up from the survey participant SEET educators and students. We then discuss our findings, with respect to the Empirical/Experience Questions (EQs) we listed in Section 1.

\subsection{Metadata on Survey Participants}

After the data clean-up (e.g., removing entries who did not agree to the terms or did not meet the inclusion criteria of the survey, etc.), we found that a total of 320 participants took the survey but 268 had actually taught or taken a SEET course online during the pandemic, yielding an approximate $84 \%$ completion rate. All the results, data analysis, etc. in the following sections are based on these 268 participants' responses.

Among the survey participants, the educator, student ratio was $16-84 \%$ - which is also reasonable since a single educator can teach a large number of students in a class. $58 \%$ of our educator participants reported it was their first time experience teaching any courses "online", while taking a class "online" was first time experience for $66 \%$ of the student participants.

Overall, we had roughly $80-20 \%$ representations of male and female participants - educators: $72-28 \%$; students: $80-19 \%$ with $1 \%$ did not disclose. The educator participants were from 18 different countries highest from USA, around 19\% and 5\% did not want to share their location; and student participants were from 11 different countries - highest from Germany, around $56 \%$ and $3 \%$ did not want to share their location. The participant educators identified their courses as mainly sophomore, junior level (i.e., $2^{\text {nd }}$ and $3^{\text {rd }}$ year) or graduate-level courses - where class sizes ranged from 5 to 700 students, with a median of 91 students.

\subsection{Transition Experience}

Even though it was first-time experience of teaching or taking any classes "remotely/online" for $58 \%$ of our survey participant SEET educators and $66 \%$ of the students, respectively - interestingly, as Table 1 and 2 show, technology adaption, access to technology or issues with the Internet were among the least challenging problems. This is probably because since SEET courses are technology-oriented courses, and as are usually taught in the $2^{\text {nd }}-3^{\text {rd }}$ years, all the educators and students became accustomed with the required technologies. Rather, among the most challenging issues for the educators were to keep students engaged and motivated during the class, assessing the course learning outcome, and also managing their own time, etc. For example, our interviewee SEET educators commented teaching remotely, online as being "looking at a black box" and feeling "being a radio presenter 


\begin{tabular}{|l|r|r|c|c|c|r|}
\hline \multicolumn{1}{|c|}{ Top Challenges } & $\mathbf{0 - n} / \mathbf{a}$ & 1-least & \multicolumn{1}{c|}{$\mathbf{2}$} & $\mathbf{3}$ & $\mathbf{4}$ & $\mathbf{5}$-most \\
\hline Student Engagement & $0 \%$ & $0 \%$ & $0 \%$ & $29 \%$ & $52 \%$ & $19 \%$ \\
\hline Course Assessment & $10 \%$ & $13 \%$ & $13 \%$ & $19 \%$ & $23 \%$ & $23 \%$ \\
\hline Time Management & $6 \%$ & $19 \%$ & $13 \%$ & $19 \%$ & $35 \%$ & $6 \%$ \\
\hline Spending Time on Emails & $3 \%$ & $6 \%$ & $29 \%$ & $26 \%$ & $26 \%$ & $10 \%$ \\
\hline Student Cheating & $29 \%$ & $26 \%$ & $3 \%$ & $6 \%$ & $26 \%$ & $10 \%$ \\
\hline Internet Issues & $0 \%$ & $42 \%$ & $16 \%$ & $10 \%$ & $23 \%$ & $10 \%$ \\
\hline Childcare & $32 \%$ & $19 \%$ & $10 \%$ & $6 \%$ & $13 \%$ & $19 \%$ \\
\hline Anxiety, Stress, Illness & $19 \%$ & $19 \%$ & $23 \%$ & $10 \%$ & $23 \%$ & $6 \%$ \\
\hline Technology Adaption & $6 \%$ & $35 \%$ & $10 \%$ & $23 \%$ & $23 \%$ & $3 \%$ \\
\hline Preparing Class Materials & $0 \%$ & $19 \%$ & $29 \%$ & $26 \%$ & $19 \%$ & $6 \%$ \\
\hline Technology Access & $10 \%$ & $39 \%$ & $26 \%$ & $16 \%$ & $10 \%$ & $0 \%$ \\
\hline Financial Hardship & $42 \%$ & $32 \%$ & $10 \%$ & $10 \%$ & $3 \%$ & $3 \%$ \\
\hline
\end{tabular}

Table 1. Top challenges educators faced, based on cumulative sum of challenge point $\geq 3$.

\begin{tabular}{|l|r|r|c|c|c|r|}
\hline \multicolumn{1}{|c|}{ Top Challenges } & $\mathbf{0 - n} / \mathbf{a}$ & 1-least & $\mathbf{2}$ & $\mathbf{3}$ & $\mathbf{4}$ & $\mathbf{5}-\mathbf{m o s t}$ \\
\hline Staying Engaged/Motivated & $2 \%$ & $6 \%$ & $11 \%$ & $19 \%$ & $22 \%$ & $40 \%$ \\
\hline Time Management & $4 \%$ & $7 \%$ & $17 \%$ & $16 \%$ & $33 \%$ & $23 \%$ \\
\hline Anxiety, Stress, Illness & $8 \%$ & $19 \%$ & $18 \%$ & $21 \%$ & $23 \%$ & $12 \%$ \\
\hline Course Assessment & $7 \%$ & $16 \%$ & $25 \%$ & $24 \%$ & $23 \%$ & $6 \%$ \\
\hline Spending Time in Emails & $4 \%$ & $23 \%$ & $22 \%$ & $27 \%$ & $18 \%$ & $7 \%$ \\
\hline Internet Issues & $4 \%$ & $45 \%$ & $23 \%$ & $14 \%$ & $10 \%$ & $4 \%$ \\
\hline Financial Hardship & $22 \%$ & $47 \%$ & $13 \%$ & $10 \%$ & $4 \%$ & $4 \%$ \\
\hline Technology Adaption & $6 \%$ & $53 \%$ & $20 \%$ & $15 \%$ & $6 \%$ & $0 \%$ \\
\hline Childcare & $68 \%$ & $23 \%$ & $4 \%$ & $3 \%$ & $1 \%$ & $1 \%$ \\
\hline Technology Access & $12 \%$ & $70 \%$ & $10 \%$ & $6 \%$ & $1 \%$ & $1 \%$ \\
\hline
\end{tabular}

Table 2. Top challenges students faced, based on cumulative sum of challenge point $\geq 3$.

without knowing if the message was going across". Similarly, students also suffered from being less motivated, struggled to stay engaged but also reported higher level of anxiety, stress and illness than the educators.

Regarding SEET course related experience or opinion, as Figure 2 shows, except for exams and quiz evaluations, educators seem to agree that "in-person" and "remote, online" do not have much difference. On the other hand, as Figure 3 shows, students think project implementation would have been easier had it been "in-person" classes.

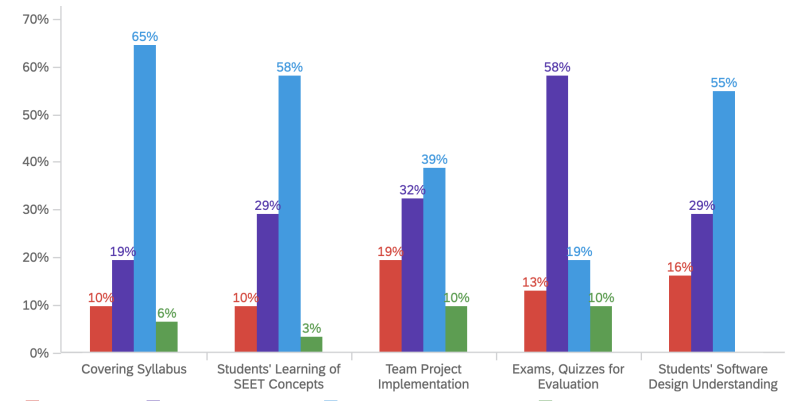

Time will tell $\square$ In-person was better $\square$ They are almost the same $\square$ Online was better

Figure 2. Educators' Perspective: Difference of SEET teaching aspects between "in-person" and "online" format.

Apart from similar advantages of "remote, online" classes found in [16], when asked about some

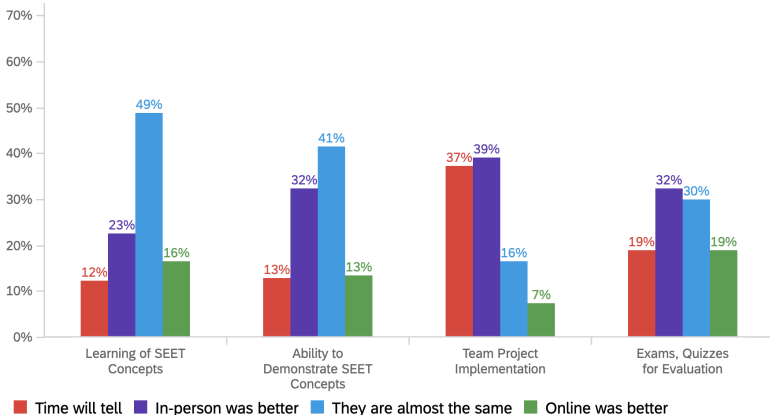

Figure 3. Students' Perspective: Difference of SEET learning aspects between "in-person" and "online" format.

advantages specific to SEET, some educators and students commented that it helped them experience "remote" collaborative work that can benefit them for possible "distributed software development" in the future.

\subsection{EQ1: Tools and Techniques Adapted}

Since the switch of teaching modality was abrupt and most of the educators did not have proper, prior training, many were forced to adapt a tool in a "trial-and-error" approach. In our interviews, we came across several educators who reported that they started with one tool and later - be it for lack of features, support; or not knowing the full potentials - had switched into other tool(s). Therefore, for all of our survey questions regarding tools and techniques, we allowed multiple-selection of options. We present all the data in percentage of response count, that is, for any tool choice option, $x \%$ of usage does not mean it was exclusively used by $\mathrm{x} \%$ participants, rather it means $\mathrm{x} \%$ responses chose that tool along with possibly other available tool(s).

\subsubsection{Tools for "Online", Video Communication} and Learning Management Systems (LMS) We wanted to know what video conferencing and communication tools the SEET educators are using for their "online" classes. As Figure 4 shows, Zoom is the the most popular tool among SEET educators, followed by Microsoft Teams. However, to our surprise, they reported "Other" tools like: YouTube[26], BigBlueButton [27], Vimeo[28], etc. which collectively secured the third most used tools' spot.

Posed with the question on what Learning Management Systems (LMS) they used for their classes, as Figure 5 shows, our survey participant 


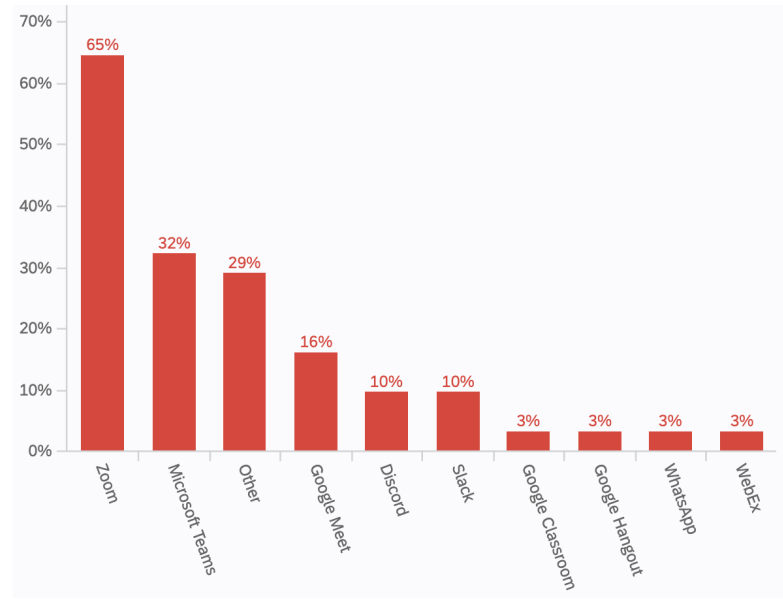

Figure 4. Video Conferencing tools SEET educators used, in descending order of usage, in percentage of responses.

educators listed commercial tools like Canvas[29] and Blackboard [30] but also majority of them used other open-source or free tools like: Moodle [31], SAKAI-based Sulis [32], Agora [33] and Piazza [34]. We must acknowledge here that we were unaware of many of these reported open-source, free LMS tools before. Some of the survey participant educators reported using university-developed, proprietary systems. However, $6 \%$ of the educators did not use any LMS for their course. These SEET educators could utilize the open-source, free tools mentioned in the "Other" group here.

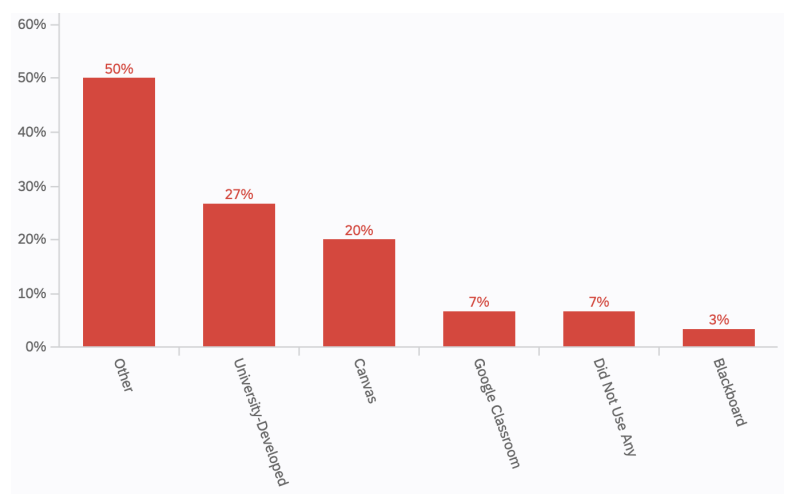

Figure 5. Learning Management Systems (LMS) SEET educators used, in descending order of usage, in percentage of responses.

4.3.2. Techniques Used for "Online" Modality of Classes On the techniques on delivering their SEET lectures online, as Figure 6 shows, survey participants educators responded with a mix of approaches: live lectures, live lectures that are recorded and posted later, flipped or inverted classroom (i.e., pre-recorded lecture videos) $[5,35]$ and by uploading only online materials (e.g., lecture slides), etc.

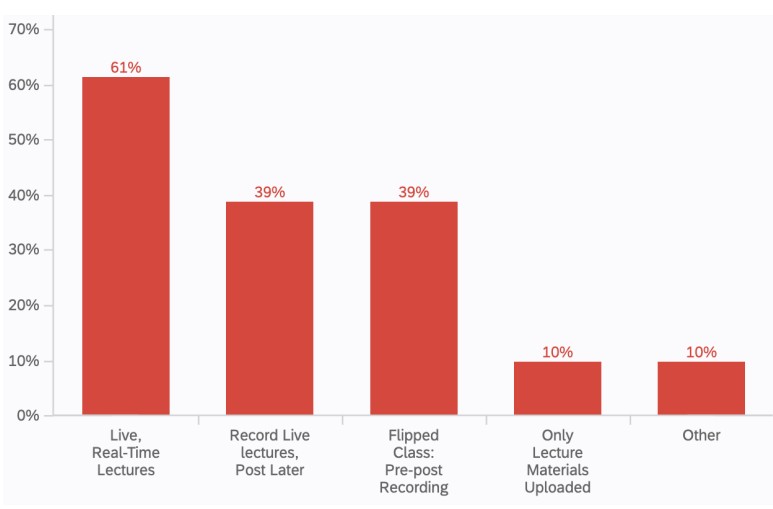

Figure 6. How educators delivered their lectures.

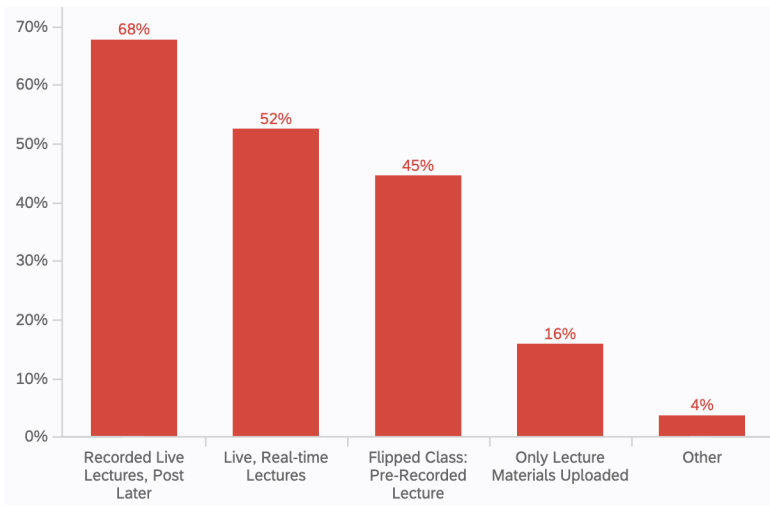

Figure 7. How students want the lectures delivered.

However, when we asked the students how they prefer these "online" classes, as shown in Figure 7, and also as we will see in Section 4.4, students mainly prefer live lectures that are recorded and posted later for their review.

In our survey, we asked the educators what changes they made into their previously "in-person" SEET courses for the transition. Separately, we also asked the students what they think is better suited for such a class. As Figures 8 and 9 show, it is encouraging to see that the top 3 items from the two groups, namely shorter online lectures; extra time for turning in homework and assignments; and changed format for quizzes and exam questions - matched, that is, the SEET educators have tried well in addressing the students' need for this teaching modality transition. 


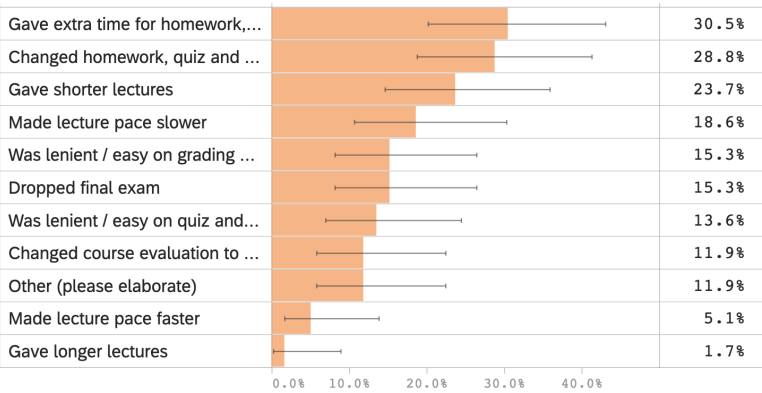

Figure 8. Changes educators made for "remote, online" classes.

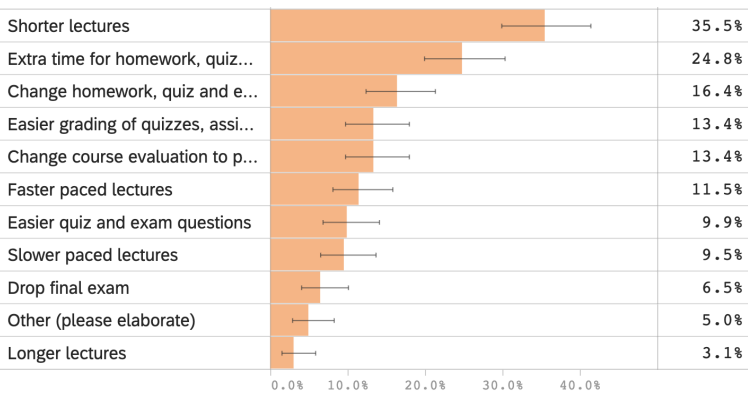

Figure 9. Changes students prefer for "remote, online" classes.

4.3.3. Tools and Techniques Used for SEET Class Activity and Student Engagement What kind of activities did SEET educators use for better student engagement in teaching their courses "online" during this pandemic? With this question in mind, we requested our survey participant educators to choose from a set of options that came up repeatedly in our prior interviews with the 16 SEET educators, as well as specify and elaborate the optional "Other" category for the question - if they had used any additional activities. Figure 10 shows that most of the educators mentioned team projects, project presentations, drawing UML and other SEET related diagrams, reading assignments, etc. as their main activity items. In addition, educators mentioned requiring their students to test and peer review each others code, finding code metrics, writing test cases and various types of theoretical exercises as "Other" activities.

One observation from the data that is not shown in Figure 10 was that when the class size is large, educators mostly focused on taking quizzes, mid-term exams, final exams and assignments. For small sized classes, educators tend to choose individual projects. In doing these kinds of activities, below we list, category-wise, names of the tools that the educators mentioned in their survey responses.

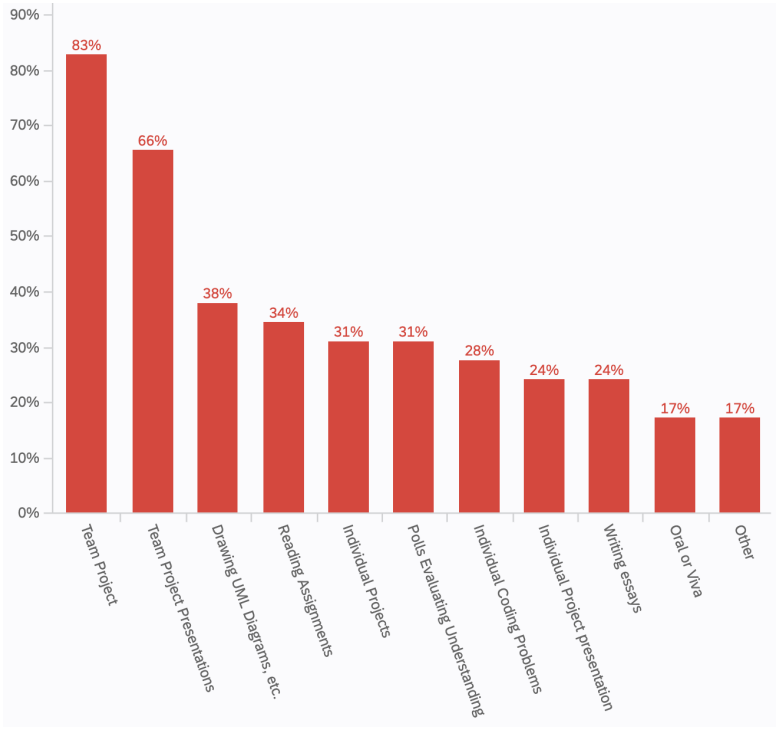

Figure 10. Types of activities educators used in their SEET courses, in descending order, in response percentage

- In-class polls and surveys: Kahoot [36], Google Forms [37], Mentimeter [38], Canvas Quiz [29]

- Drawing UML and other diagrams: Aww App [39], draw.io/diagram.net [40], whiteboard [41, 42], Lucidchart[43]

- Online Grading: Gradescope [44]

- Online coding and contribution: Repl.it [45], RepoSense [46] and GitHub [47]

Some SEET educators mentioned using "online polling" during class lecture as a remedy to the lack of students' class engagement problem. Recently, Zoom introduced live polling and result sharing feature in their meeting app [48]. Educators also mentioned using Zoom's breakout rooms with smaller groups of students for class discussions to be useful. Another suggestion was to use social activities, e.g., virtual scavenger hunt [49] or utilizing game-based tools like Kahoot[36] for team building.

\subsection{EQ2: Lessons Learned and Improvement Suggestions}

We asked both our survey participant educators and students for their feedback on lessons learned and improvement suggestions on "remote, online" modality of SEET classes. In this section, we summarize and comment on some of these reflections.

Some common improvement suggestions from the SEET educators for themselves were: to get training in 
e-learning; research and experiment more with distance learning tools and technology; replace lengthy midterms with shorter weekly or bi-weekly graded assignments; have more synchronous, live but short lectures; use more interactive tools for micro surveys on lecture contents; find ways to have students keep their cameras on; shorter class sizes and pre-recorded videos that discussed review questions for quizzes and exams, etc.

Interestingly, students' suggestions were aligned with what educators reflected on. For example, as one of the students comment below shows, students prefer recorded lectures but not as a replacement for the live classes. Moreover, they also realize the importance of keeping their cameras "on" for the real-time feedback for the educators as well as keeping their attention:

"Make everything available live and only publish recordings later to encourage direct viewing. Teachers should obligate us to turn on our cameras, [for our] attention."

To improve participation and class engagement, as the student comment below shows, students think that there should be more ways for "anonymous" communication using chat or other tools and ways for them to provide feedback on the class lecture speed:

'Students' minds tend to wander off. Communicate more with the students through a chat or $Q A$ Session. [Use] platforms for asking questions in text form and signaling speed of lecture. Shorter lectures and longer tutorials. Add live events for questions etc."

There were also improvement suggestions from students for quizzes, assignment and final exams. The suggestions mainly focus on adapting the online format for these assessments, as one comment suggests:

"Teachers try too hard to grade students in the same ways they did before, doing weekly exams with final project instead of final tests [would be better]."
One interesting student comment below that binds agile concepts to the "online" teaching, was to take frequent feedback from the students on the class itself and adjust accordingly:

"Moving away from traditional classroom models (akin to waterfall) towards agile processes such as scrumming to get pulse checkups from students."

Finally, not regarding the classes but for the university administrators, SEET educators commented that this pandemic has brought up many limitations and loopholes in their policies. For example, many universities were prompt to relax their restrictions on students' physical location requirements and worked closely with the governments to accommodate any other needs in an ad-hoc basis. A lesson learned from this experience was that universities should have clear guidelines, directions and contingency plans for their students in preparation for such pandemics in the future.

\section{Threats to Validity}

This study was a multi-step study and for each step we tried to ensure an equal and representative distribution of participants (i.e., interviewees and survey participants). However, we acknowledge that, even with our best efforts, we may not have reached enough audience and hence may have missed many data points. For example, we could not find any SEET educators to interview from countries in South America. For our surveys, we used social media, emails and personal contacts and solicited SEET educator and student participation and yet the sample size for educators were still small (16\% of the total $300+$ participants). Moreover, majority of the participants were from North America, Europe and Australia and we did not get much participation from countries from South America, Middle East, Africa or Asia. As a result, the results may be skewed towards these regions. This situation may have stemmed from the fact that software engineering is a specialized course which many universities may not simply offer or have not offered during this pandemic.

Low female participation from both the educators and students is another limitation that we observed from our data set. However, this may be expected as previous studies have already found that there is a significant gap in gender distribution in software engineering practitioners in both academia and industry $[50,51,52,53]$. 
Like any other online surveys, our study is also prone to many other possible limitations [54]. For example, we filtered out participants if they did not participate in university-level SEET courses "online" during this pandemic, but there is always the possibility that someone who did not fit our inclusion criteria figured it out and took the survey the second time and introduced noise in the data. Moreover, since the survey questions were in English, many non-English speaking participants may not have understood or misunderstood a question and provided altered input.

With these limitations, we acknowledge that this study and its findings may have missed many important observations, challenges and limitations and the corresponding tools and techniques to handle them.

\section{Discussion}

Though technology adaption, access to resources like laptops and Internet were not the main bottlenecks, many educators were forced to consider and mediate different other situations, e.g., different time-zones of local and international students, data privacy, legal obligation on taking permission prior to recording classes with students names and images visible, and student integrity issues during online exams, etc. For under developed or developing countries, limited access to Internet, Internet infrastructure, e.g., lack of $\mathrm{WiFi}$, hotspot and bandwidth issues, etc. further hindered the transition.

On the flip side, there were some advantages of "online" classes. One common, repeated theme was that since classes were recorded, students could review the material later, the "flipped, inverted format" of class allowed students to ask more questions during the class times; chat and other communication mediums helped the shy students participate more in the digital discussions. Though we this could not be verified, some educators reported better overall student grades and student evaluation of teaching. Some students and educators also thought that virtual team projects helped them experience distributed software development that could be valuable for future job placements.

Different educators in different countries may have different approaches in teaching SEET courses, their situations are unique which may mandate use of different tools and there is no "one size fits all" approach. Therefore, the motivation behind asking these experience/empirical questions to our interviewees and later to our survey participants was not to compare, prioritize or recommend any of the tools or techniques; rather to share these with the broader SEET community to make them aware and leave it to them to try out and decide which may be helpful. A list of such tools are provided in Section 4.3.

Our findings show that overall the SEET educators are doing well in adapting the changes that reflects students' expectations and needs. However, going forward, when the pandemic is over and the "remote/online" classes are no longer required, as suggested in Section 4.4, we propose that SEET and other educators should incorporate the positive aspects and improvement suggestions, e.g., recording class lectures, providing tools for anonymous communication, micro survey/polling on lecture content, collaborative and interactive tools for drawing UML and other SEET diagrams, etc. into their regular "in-person" (or "hybrid") classes in the future. We also propose that, instead of waiting for the student evaluation at the end of a semester, a mid-term, anonymous "Mad-Sad-Glad" survey $[55,56]$ should be used as a useful tool to check the students' "pulses" and get their feedback on the overall course speed, quality and further improvement suggestions.

As future research direction, one can extend this study to include more participants, world-wide and also find the impacts of this pandemic to the overall SEET learning outcome and future software engineers working in the industry, workforce, etc., in the long run.

\section{Conclusion}

In this paper we performed a qualitative study by conducting semi-structured interviews of 16 Software Engineering Education and Training (SEET) educators; followed by quantitative surveys of more than 300 educators and students who were part of SEET courses that had to be switched from "in-person" to "remote, online" mode due to the novel coronavirus (COVID-19) pandemic. The goal of this empirical study was to find out the tools and techniques SEET educators adapted for the transition, and get their and the students' reflection on the lessons learned and the improvement suggestions.

Despite all our efforts, our study was not able to capture all the important data points that would represent the global SEET community. However, we share the transition experience and provide the tools and means that the educators are using in an attempt to overcome them. Many of these tools and techniques were unknown to us before the study and we believe that educators will find these useful in combating their challenges. We also contribute by publishing our survey data for further study and collaboration [1]. 


\section{Acknowledgments}

We would like to sincerely thank all of the interview participants for their valuable time during this pandemic in virtually sitting down with us "online", discussing and sharing their experience. We want to also thank all of the survey participants for their valuable feedback.

\section{References}

[1] "Survey questions and responses for the paper. https: //bit.1y/seetcov19."

[2] A. D. Dumford and A. L. Miller, "Online learning in higher education: exploring advantages and disadvantages for engagement," Journal of Computing in Higher Education, vol. 30, no. 3, pp. 452-465, 2018.

[3] D. R. Serrano, M. A. Dea-Ayuela, E. Gonzalez-Burgos, A. Serrano-Gil, and A. Lalatsa, "Technology-enhanced learning in higher education: How to enhance student engagement through blended learning," European Journal of Education, vol. 54, no. 2, pp. 273-286, 2019.

[4] B. Quinn, L. Barroca, B. Nuseibeh, J. Fernández-Ramil, L. Rapanotti, P. Thomas, and M. Wermelinger, "Learning software engineering at a distance," IEEE software, vol. 23, no. 6, pp. 36-43, 2006.

[5] G. Gannod, J. Burge, and M. Helmick, "Using the inverted classroom to teach software engineering," in 2008 ACM/IEEE 30th International Conference on Software Engineering, pp. 777-786, IEEE, 2008.

[6] M. Jacobsen, R. Kremer, and M. L. Shaw, "Experiments with distance learning in software engineering graduate courses," ACM SIGCSE Bulletin, vol. 32, no. 2, pp. 56-59, 2000.

[7] K. Yoshida, I. Miyaji, K. Yamada, and H. Ichimura, "Distance learning system for programming and software engineering," in International Conference on Knowledge-Based and Intelligent Information and Engineering Systems, pp. 460-468, Springer, 2007.

[8] E. Cloete, "Some perspectives on network centric distance learning and software engineering," in Proceedings 7th IEEE Workshop on Future Trends of Distributed Computing Systems, pp. 288-289, IEEE, 1999.

[9] S. Edwards, "Can quality graduate software engineering courses really be delivered asynchronously on-line?," in Proceedings of the 22nd international conference on Software engineering, pp. 676-679, 2000.

[10] H. J. Ellis, "Autonomous learning in online and traditional versions of a software engineering course," in 18th Conference on Software Engineering Education \& Training (CSEET'05), pp. 69-76, IEEE, 2005.

[11] W. Wang, "Teaching programming online," in International conference on the future of education. Retrieved from http://www. pixelonline. net/edu_future/common/download/Paper_pdf/ELE19-Wang. pdf, 2011.

[12] C. Murphy, D. Phung, and G. Kaiser, "A distance learning approach to teaching extreme programming," in Proceedings of the 13th annual conference on Innovation and technology in computer science education, pp. 199-203, 2008.
[13] A. T. Ragusa and A. Crampton, "Sense of connection, identity and academic success in distance education: Sociologically exploring online learning environments," Rural Society, vol. 27, no. 2, pp. 125-142, 2018.

[14] J. E. Seaman, I. E. Allen, and J. Seaman, "Grade increase: Tracking distance education in the united states.," Babson Survey Research Group, 2018.

[15] I. E. Allen and J. Seaman, Online report card: Tracking online education in the United States. ERIC, 2016.

[16] O. B. Adedoyin and E. Soykan, "Covid-19 pandemic and online learning: the challenges and opportunities," Interactive Learning Environments, pp. 1-13, 2020.

[17] R. M. Viner, S. J. Russell, H. Croker, J. Packer, J. Ward, C. Stansfield, O. Mytton, C. Bonell, and R. Booy, "School closure and management practices during coronavirus outbreaks including covid-19: a rapid systematic review," The Lancet Child \& Adolescent Health, 2020.

[18] M. V. Shenoy, M. S. Mahendra, and M. N. Vijay, "Covid 19-lockdown: Technology adaption, teaching, learning, students engagement and faculty experience," Mukt Shabd Journal, vol. 9, 2020.

[19] W. Bao, "Covid-19 and online teaching in higher education: A case study of peking university," Human Behavior and Emerging Technologies, vol. 2, no. 2, pp. 113-115, 2020.

[20] S. Motogna, A. Marcus, and A.-J. Molnar, "Adapting to online teaching in software engineering courses," in Proceedings of the 2nd ACM SIGSOFT International Workshop on Education through Advanced Software Engineering and Artificial Intelligence, pp. 1-6, 2020.

[21] T. Kanij and J. Grundy, "Adapting teaching of a software engineering service course due to covid-19," in 2020 IEEE 32nd Conference on Software Engineering Education and Training (CSEE\&T), pp. 1-6, IEEE, 2020.

[22] M. Barr, S. W. Nabir, and D. Somerville, "Online delivery of intensive software engineering education during the covid-19 pandemic," in 2020 IEEE 32nd Conference on Software Engineering Education and Training (CSEE\&T), pp. 1-6, IEEE, 2020.

[23] M. Mues and F. Howar, "Teaching a project-based course at a safe distance: An experience report," in 2020 IEEE 32nd Conference on Software Engineering Education and Training (CSEE\&T), pp. 1-6, IEEE, 2020.

[24] P. Schmiedmayer, L. M. Reimer, M. Jovanović, D. Henze, and S. Jonas, "Transitioning to a large-scale distributed programming course," in 2020 IEEE 32nd Conference on Software Engineering Education and Training (CSEE\&T), pp. 1-6, IEEE, 2020.

[25] M. Moster, D. Ford, and P. Rodeghero, ““is my mic on?" preparing se students for collaborative remote work and hybrid team communication," in 2021 IEEE/ACM 43rd International Conference on Software Engineering: Software Engineering Education and Training (ICSE-SEET), pp. 89-94, IEEE, 2021.

[26] "YouTube. An online video sharing platform from Google. https: / / www . youtube.com/."

[27] "BigBlueButton. An open-source web conferencing tool. https: / /bigbluebutton.org/."

[28] "Vimeo. An American video hosting, sharing and service platform. https://vimeo.com/." 
[29] "Canvas. A web based learning management system. https: / / www. instructure.com/canvas/."

[30] "Blackboard. A web-based learning management system. https: / / www.blackboard.com/."

[31] "Moodle. A free, open-source course management system. https://moodle.org/."

[32] "Sakai - a free, online learning management system. https://www.sakailms.org/."

[33] "Agora Learning. https://www. agora-learning.com/."

[34] "Piazza - a free, online forum-style platform for asking questions. https://piazza.com/."

[35] B. Tucker, "The flipped classroom," Education next, vol. 12, no. 1, pp. 82-83, 2012.

[36] "Kahoot - online game-based learning. https:// kahoot.com/."

[37] "Google Forms. Free online survey administration software from Google. https://www.google. com/forms/about/.'

[38] "Mentimeter - free, online software for interactive presentation with real-time audience feedback. https: //www. mentimeter.com/."

[39] "Aww App. A web based touch-friendly whiteboard for collaboration https : / /www . awwapp. com/."

[40] "Draw.io - a free, online tool for drawing flowcharts, UML diagrams, etc. https://app.diagrams. net /."

[41] "Microsoft whiteboard. https:// www.microsoft.com/en-ca/ microsoft-365/microsoft-whiteboard/ digital-whiteboard-app."

[42] "Free online whiteboard tool for teachers and classrooms. https: / /whiteboard.fi/."

[43] "Lucidchart - a proprietary online tool for collaborating and sharing charts, graphs, etc. https://www. lucidchart.com/.'

[44] "Gradescope - online tool for grading paper-based, digital and code assignments. https://www. gradescope.com/."

[45] "Repl.it - an online, free integrated development environment (IDE for coding) https: / / repl.it/."

[46] "RepoSense - a contribution analysis tool for Git repositories. https: / / reposense.org/."

[47] "GitHub. A hosting service for software development and version control using Git https://github. $\mathrm{com} / . "$

[48] "Zoom polling. https: / / support. zoom.us/hc/en-us/articles/

213756303-Polling-for-meetings," 2020.

[49] "Online scavenger hunt game. https:// watsonadventures.com/virtual-games/."

[50] A. Murphy, B. Kelly, K. Bergmann, K. Khaletskyy, R. V. O'Connor, and P. M. Clarke, "Examining unequal gender distribution in software engineering," in European Conference on Software Process Improvement, pp. 659-671, Springer, 2019.

[51] B. Vasilescu, D. Posnett, B. Ray, M. G. van den Brand, A. Serebrenik, P. Devanbu, and V. Filkov, "Gender and tenure diversity in github teams," in Proceedings of the 33rd annual ACM conference on human factors in computing systems, pp. 3789-3798, 2015.
[52] B. Vela, P. Cáceres, and J. M. Cavero, "Participation of women in software engineering publications," Scientometrics, vol. 93, no. 3, pp. 661-679, 2012.

[53] M. Burnett, A. Peters, C. Hill, and N. Elarief, "Finding gender-inclusiveness software issues with gendermag: a field investigation," in Proceedings of the 2016 CHI Conference on Human Factors in Computing Systems, pp. 2586-2598, 2016.

[54] H. Matsuo, K. P. McIntyre, T. Tomazic, and B. Katz, "The online survey: Its contributions and potential problems," 2004.

[55] "Mad-Sad-Glad retrospective. https://www. retrium.com/retrospective-techniques/ mad-sad-glad."

[56] E. Tuzun, H. Erdogmus, and I. G. Ozbilgin, "Are computer science and engineering graduates ready for the software industry? experiences from an industrial student training program," in 2018 IEEE/ACM 40th International Conference on Software Engineering: Software Engineering Education and Training (ICSE-SEET), pp. 68-77, 2018. 